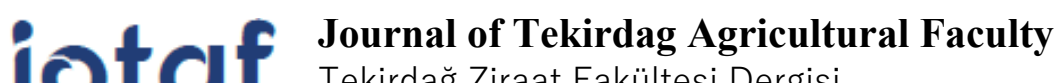 \\ Tekirdağ Ziraat Fakültesi Dergisi
}

\section{Manisa İli Pamuk Alanlarında Helicoverpa armigera Hübner (Lepidoptera; Noctuidae)'nın Bazı Biyolojik Özelliklerinin Belirlenmesi*}

Determination of Some Biological Parameters of Helicoverpa armigera Hübner (Lepidoptera; Noctuidae) on Cotton in Manisa Province

\section{Samet MEMIȘ $^{1} \quad$ Ali ÖZPINAR ${ }^{2}$}

\section{Özet}

Çalışma, Manisa ili pamuk alanlarında Helicoverpa armigera Hübner (Lepidoptera; Noctuidae)'nın bazı biyolojik özelliklerini belirlemek amacıyla 2018-2019 yıllarında yürütülmüştür. Her iki yılda da Manisa ili Şehzadeler ilçesi ve köylerindeki pamuk alanlarını temsil edecek şeklide üreticilere ait 5 farklı deneme parseli belirlenmiştir. Pamuk, 2018 y1lında 14-21 Nisan tarihlerinde ekilmiş Aphis gossypii, Empoasca spp, ve Tetranychus urticae'ye karşı bir kez ilaçlama yapılmıştır. Pamuk ekimi 2019 yılında ise 25-27 Nisan tarihlerinde 2 farklı (Carisma ve BA 440) tohum çeşidi kullanılarak yapılmıştır. Tüm parsellerde A. gossypii, Empoasca spp, ve Bemisia tabaci'e karş1 5 kez ve $H$. armigera' ya karşı ise $2 \mathrm{kez}$ olmak üzere toplam 7 farklı tarihte insektisit uygulanmıştır. H. armigera ergin popülasyon gelişmesi delta ve funnel tuzaklarla takip edilmiştir. Haftada bir kez tuzaklara yakalanan erginler sayılmış, her parselde 3 farklı yerde 3 metre bitki sırasında $H$. armigera yumurta ve larvaları ile Chrysoperla carnea (Stephens) (Neuroptera: Chrysopidae)'nın yumurtaları kaydedilmiştir. İlk yılda Karaağaçlı'da 2, Selimşahlar'da 1, Yenimahmudiye'de 2, Mütevelli'de 10 ve Veziroğlu'nda 1 adet olmak üzere toplam 16 adet $H$. armigera ergini tuzaklara yakalanmıştır. Ergin popülasyon yoğunluğu düşük düzeyde kaldığı için bu veriler değerlendirilmemiştir. Çalışmanın devam ettiği 2019 yılında ise H. armigera'nın ergin uçuşu tüm parsellerde temmuz ayının ilk haftasından itibaren başlamış olup, ağustos ortasında ve eylül ayı sonunda olmak üzere 2 tepe noktası meydana gelmiştir. Ergin uçuşu hasat tarihine (19.10.2019) kadar devam etmiştir. Örnekleme süresince her iki tuzağa Karaağaçlı'da 101, Selimşahlar'da 83, Yenimahmudiye'de 55, Mütevelli'de 77 ve Veziroğlu'nda 118 adet olmak üzere tuzaklara toplam 434 H. armigera ergini yakalanmıştır. Parsel başına en fazla H. armigera ergin BA 440 pamuk tohumu kullanılarak ekilen Karaağaçlı ve Veziroğlu parsellerinde elde edilmiştir. Diğer taraftan tüm parsellerde funnel tuzaklara yakalanan $H$. armigera ergin sayıları delta tuzaklara göre yüksek çıkmıştır. Örnekleme parsellerinde gerek emici böceklere karşı ve gerekse H. armigera (2 kez) karşı insektisit kullanılmasına rağmen, her parselde $3 \mathrm{~m}$ bitki sırasında, diğer genel predatör türlere göre, yüksek sayıda C. carnea yumurtası sayılmıştır. Parsellerde kaydedilen $H$. armigera'nın yumurta ve larva popülasyon gelişmesiyle $C$. carnea yumurta sayısı arasında bir paralellik olduğu görülmüştür.

Anahtar Kelimeler: Manisa, Pamuk, Funnel ve Delta tuzak, Helicoverpa armigera, Chrysoperla carnea

\begin{abstract}
The study was conducted on the cotton fields of Şehzadeler district in Manisa province with the purpose of determining some biological parameters of Helicoverpa armigera Hübner (Lepidoptera; Noctuidae) in 2018 and 2019. In both years, 5 different experimental parcels were selected to represent the cotton fields of Şehzadeler

${ }^{1}$ Samet Memiş, Çanakkale Onsekiz Mart Üniversitesi, Ziraat Fakültesi, Bitki Koruma Bölümü, Çanakkale; E-mail: ziraatmuh_samet@hotmail.com (iD OrcID: 0000-0002-1431-8883.

Atıf/Citation: Memiş, S., Özpınar, A. Manisa ili pamuk alanlarında Helicoverpa armigera Hübner (Lepidoptera; Noctuidae)'nın bazı biyolojik özelliklerinin belirlenmesi. Tekirdağ Ziraat Fakültesi Dergisi, 17 (3), 369-380.

*Bu çalıșma Samet Memiş'in Yüksek Lisans tezinden özetlenmiștir.

CBu çalışma Tekirdağ Namık Kemal Üniversitesi tarafindan Creative Commons Lisansı (https://creativecommons.org/licenses/by-nc/4.0/) kapsamında yayınlanmıştır. Tekirdağ 2020
\end{abstract}



district. In 2018, cotton was sowed in $14^{\text {th }}-21^{\text {st }}$ of April, one chemical control was applied against Aphis gossypii, Empoasca spp, and Tetranychus urticae. In 2019, cotton was sowed in 25-27 April with two different cultivars (Carisma and BA 440). A total of 7 insecticides applications were made with 5 times against A. gossypii, Empoasca spp, and Bemisia tabaci, two times against $H$. armigera. Adult population development of $H$. armigera was followed with delta and funnel traps. Samplings were made once a week, the number of adults were recorded and the number of $H$. armigera eggs and larvae and eggs of Chrysoperla carnea (Stephens) (Neuroptera: Chrysopidae) were counted on 3 different points on $3 \mathrm{~m}$ plant lines in all parcels. In the first year, a total of 16 adults were captured with 2 from Karaağaçlı, 1 from Selimşahlar, 2 from Yenimahmudiye, 10 from Mütevelli and 1 from Veziroğlu. Because of the low population density of adults, the data were not evaluated. In 2019, adult flight of $H$. armigera has started at the first week of July on all parcels and two peak points, in the middle of August and at the end of September, were recorded. Adult flight has continued until the harvest date (19.10.2019). A total of 434 adults were captured on all traps with 101 from Karaağaçlı, 83 from Selimşahlar, 55 from Yenimahmudiye, 77 from Mütevelli and 118 from Veziroğlu throughout the sampling period. The highest number of H. armigera adults captured per parcel was on Karağaçlı and Veziroğlu, which was sowed with BA 440 cultivar. On the other hand, the number of H. armigera adults captured were higher in funnel traps than delta traps in all parcels. Number of C. carnea eggs were higher than other predators on $3 \mathrm{~m}$ plant lines, even with 2 insecticide applications against $H$. armigera and other pests. A parallel trend was observed between the egg and larval population of H. armigera and the number of $C$. carnea eggs.

Keywords: Manisa, Cotton, Funnel and delta traps, Helicoverpa armigera, Chrysoperla carnea 


\section{Giriș}

Pamuk (Gossypium hirsitum) tropik ve subtropik alanlarda lif ve yağ elde etmek amaciyla yetiştirilen stratejik öneme sahip bir kültür bitkisidir. Ülkemizde başta Güneydoğu Anadolu Bölgesi (\%62) olmak üzere, Ege (\%16) ve Akdeniz bölgelerinde (\%21) toplam 4.944.865 dekar alanda pamuk yetiştirilmektedir (TUİ, 2020). Son yıllarda Manisa ilinde özellikle pamuk ekim alanlarında önemli artış görülmüş ve üretim alanları 90.360 dekara ulaşmıştır. Pamuk üretim alanlarının artmasıyla bitki koruma sorunları da önem kazanmış ve toplam girdilerin \%40’nı ilaç ve ilaçlama maliyeti oluşturmuştur. Pamuk üretim döneminde farklı zamanlarda Aphis gossypii (Glower), Bemisia tabaci (Gmell.), Tetranychus urticeae (Koch), Empoasca spp. ve Helicoverpa armigera Hübner ile mücadeleye ihtiyaç duyulmuştur (Anonim, 2017). Birçok ülkede farklı kültür bitkilerinde zararlı olan $H$. armigera larvalarının, pamuğun generatif organlarında yaptığı zararın, üründe ekonomik kayıplara neden olduğu bildirilmiştir (Zalucki ve ark., 1994); (Karim, 2000); (Liu ve ark., 2004). Ülkemizde ise y1llara göre değişmekle birlikte H. armigera'nın pamukta ürün kayıplarına neden olduğu ve en az iki kez ilaçlı mücadeleye ihtiyaç duyulduğu belirtilmiştir (Öngören ve ark., 1977); (Karaat ve ark., 1986); (Göven ve Efil, 1994); (Mart ve ark., 2000); (Atakan ve Boyacı 2017); (Akyıldız ve Bayhan, 2018).

Helicoverpa armigera larvalarının pamuk bitkisindeki beslenme davranışı nedeniyle uygulanan kimyasallarla temasının yeterince sağlanamaması mücadelenin başarısını düşürmektedir. Diğer taraftan H. armigera ile ilgili olarak yapılan çalışmaların pek çoğunda örneklenen ergin sayılarıyla ergin öncesi dönemleri arasındaki tutarsızlıklara işaret edilmiştir. Nitekim, kullanılan cinsel çekici feromon tuzaklarına yakalanan ergin sayısıyla $H$. armigera'nın ergin öncesi dönemleri arasındaki ilişkinin zayıf olduğu, bu nedenle mücadelede arzu edilen başarının sağlanamadığı bildirilmiştir (Mart ve ark., 2000). Ergin örneklemede kullanılan cinsel çekici feromonun kimyasal yapısının uyumsuzluğu yanında, tuzak şekillerinin de önemli olduğu bilinmektedir. H. armigera'nın salgın yıllarında zararlı ile mücadelenin başarısı için pamuk üreticileri kimyasal mücadeleye gereğinden fazla başvurmaktadır. Ayrıca, son yıllarda emici böceklerin erken dönemlerde pamukta zararlı olması da insektisit kullanımını arttırmaktadır. Bu durum $H$. armigera'nın üzerinde etkili olan parazitoit ve predatör türlerin popülasyon gelişmelerine sekteye uğratmaktadır (Özgür ve ark.,1988). Bağlantılı olarak domates alanlarında zararlılara karşı gereğinden fazla insektsit kullanılması sonucu, yararlı türlerin azalmasıyla yaprakbiti ve kırmızı örümceklerin popülasyon yoğunluğu artmıştır (Özpınar ve ark., 2017b). Bu nedenle, pamuktaki zararlılara karşı kullanılan insektisitlerin genel predatör türler üzerindeki yan etkileri değişik araştırıcılar tarafından incelenmiştir (Ferreira ve ark., 2006); (Tilman ve Mulrooney, 2000); (Sechser ve ark., 2003). Bu türlerden Chrysoperla carnea (Stephens)'nın insektisitlere daha toleranslı olduğu belirlenmiştir (Theiling ve Croft, 1988); (Sayyed ve ark., 2010).

$\mathrm{Bu}$ çalışmada, Manisa ili Şehzadeler ilçesi sınırlarında yer alan 5 farklı pamuk tarlasında H. armigera erginlerini yakalamada delta ve funnel tipi tuzaklar karşılaştırılmış ve zararlının mücadelesine 1şık tutacak bazı biyolojik parametreler incelenmiştir.

\section{Materyal ve Metot}

Çalışma, 2018 ve 2019 yıllarında Manisa İli Şehzadeler ilçesi ve köylerinde belirlenen üreticilere ait 5 adet pamuk tarlasında yürütülmüştür. Pamuk ekimi 2018 yılında 14-21 Nisan tarihlerinde yapılmış ve ekim ayının ortasında hasat edilmiştir. Temmuz ve ağustos sonunda olmak üzere 2 sulama yapılmış ve yetiştirme mevsimi boyunca A. gossypii, Empoasca spp, ve T. urticae ile mücadelede ruhsatlı ilaçlar kullanılmıştır.

İkinci yıl çalışmaları için 2019 yılında ise belirlenen parsellerde 25-27 Nisan tarihlerinde Tablo 1'de belirtilen Carisma ve BA-440 pamuk tohumları kullanılarak ekim yapılmış ve 19-22 Ekim tarihlerinde hasat edilmiştir. BA440 çeşidinin yapraklarının daha tüylü olması dışında, diğer özellikleri Carisma çeşidi ile benzerdir. Pamuğun bakımı üreticiler tarafından yapılmış olup, temmuz ve ağustos aylarında 2 kez sulanmış ve tüm parsellerde $A$. gossypii, Empoasca spp ve B. tabaci 'ye karşı farklı tarihlerde 5 kez, ilave olarak da H. armigera için 2 kez olmak üzere tüm parsellerde toplam 7 kez ilaçlama yapılmıştır.

Helicoverpa armigera'nın ergin popülasyon gelişmesinin takibi, 2 mg Z-11 Hexadecenal+0,08 mg Z-9 Hexadecenal kimyasal yapısındaki ruhsatlı feromon kapsülü içeren delta ve funnel tipi tuzaklarla yapılmıştır. Tuzaklar her parselde birer adet olacak şekilde 2018 yılında 25 Haziran'da ve 2019 yılında ise 06 Temmuz tarihlerinde yerleştirilmiştir (Şekil 1). Sayımlar, H. armigera erginleri tuzaklara yakalanana kadar günlük ve erginler yakalandıktan sonra ise haftada bir kez olacak şekilde periyodik olarak devam etmiştir. Tuzakların 
Manisa ili pamuk alanlarında Helicoverpa armigera Hübner (Lepidoptera; Noctuidae)'nın bazı biyolojik özelliklerinin belirlenmesi feromonu dört hafta arayla ve delta tipi tuzaklardaki yapışkan tabla ise kirlendikçe yenisiyle değiştirilmiştir. Her iki yılda da pamuk hasadıyla birlikte tuzaklardaki sayımlar sonlandırılmıştır. İlk yılda $H$. armigera popülasyon yoğunluğu düşük olduğu için yeterli bulguya ulaşılmayınca değerlendirme yapılamamıştır.

Tablo 1. Deneme alanlarının özellikleri ve 2019 yllında yapılan uygulamalar

Table 1. Properties of the trial areas and applications in 2019

\begin{tabular}{|c|c|c|c|c|c|c|}
\hline Parsel adı & $\begin{array}{l}\text { Ekim } \\
\text { tarihi }\end{array}$ & $\begin{array}{l}\text { Pamuk } \\
\text { çeşidi }\end{array}$ & $\begin{array}{l}\text { Alan } \\
\text { (da) }\end{array}$ & $\begin{array}{l}\text { Kullanilan } \\
\text { insektisitler }\end{array}$ & $\begin{array}{l}\text { Uygulama } \\
\text { tarihleri }\end{array}$ & Zararlı etmenler \\
\hline Karaağaçl1 & 25.04 .2019 & BA 440 & 20 & \multirow{5}{*}{$\% 20$ Acetamiprid } & $12-15.05 .2019$ & Aphis gossypii, Empoasca spp \\
\hline Selimşahlar & 27.04 .2019 & Carisma & 60 & & $27-29.05 .2019$ & Empoasca spp \\
\hline Y.mahmudiye & 26.04 .2019 & Carisma & 40 & & $10-12.06 .2019$ & Empoasca spp \\
\hline Mütevelli & 27.04 .2019 & Carisma & 30 & & $25-29.06 .2019$ & Empoasca spp \\
\hline \multirow[t]{3}{*}{ Veziroğlu } & 25.04 .2019 & BA 440 & 50 & & $21-24.08 .2019$ & Aphis gossypii, Bemisia tabaci \\
\hline & & & & \multirow{2}{*}{$\begin{array}{l}\text { Chlorantraniliprole } \\
\text { 50g+Lambda- } \\
\text { cyhalothrin ZC }\end{array}$} & $21-24.08 .2019$ & Helicoverpa armigera \\
\hline & & & & & $20-25.09 .2019$ & Helicoverpa armigera \\
\hline
\end{tabular}

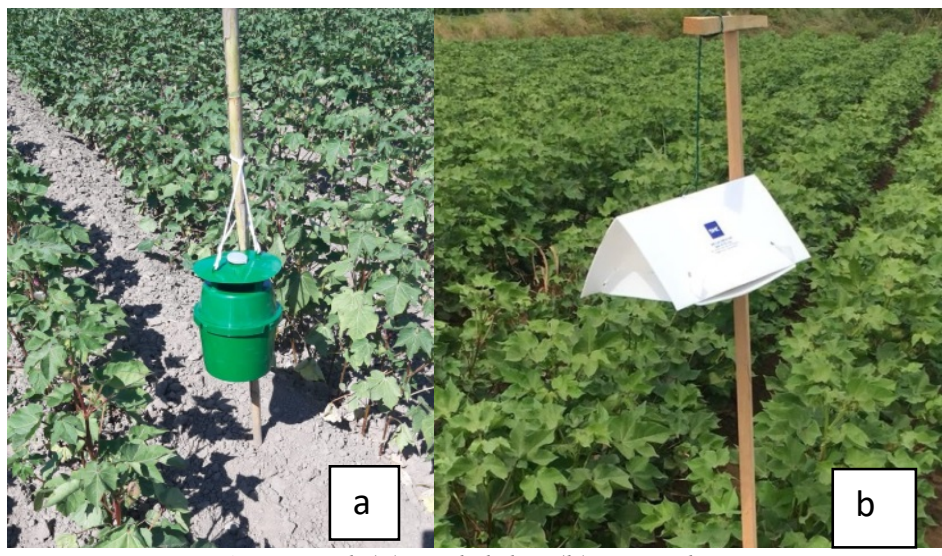

Figure 1. Funnel (a) and delta (b) type pheromone traps

Şekil 1. Funnel (a) ve delta (b) tipi feromon tuzaklart

Çalışmanın ikinci yılı olan 2019 yılında elde edilen bulgular örnekleme yerleri ve tarihleri esas alınarak funnel ve delta tipi tuzaklara yakalanan ergin sayıları SPSS 23 istatistik paket programı (IBM Crop, 2015) kullanılarak $(\mathrm{P}<0,05)$ tek yönlü ANOVA uygulanarak aralarındaki fark karşılaştırılmıştır.

Ayrıca, her parselde 3 farklı yerde, 3 metre bitki sırasında $H$. armigera'nın ergin öncesi dönemleri (yumurta ve larva) ve doğal düşmanlarından C. carnea'nın yumurta sayıları kaydedilmiştir. H. armigera'nın ergin öncesi dönemleriyle $C$. carnea arasındaki ilişki parsel düzeyinde grafiklerle değerlendirilmiştir.

\section{Araştırma Sonuçları ve Tartışma}

Çalışmanın ilk yılında pamuk yetiştirme periyodu boyunca 26.06.2018-15.09.2018 tarihlerinde Karaağaçlı'da 2, Selimşahlar'da 1, Yenimahmudiye'de 2, Mütevelli'de 10 ve Veziroğlu'nda 1 adet olmak üzere tuzaklara toplam 16 adet $H$. armigera ergini tuzaklara yakalanmıştır. $H$. armigera'nın salgın yılında olmaması nedeniyle ergin popülasyon yoğunluğu düşük düzeyde kaldığı için ilk yılın verileri değerlendirilmemiştir.

Denemenin ikinci yılında ise 06.07.2019 tarihinde parsellere yerleştirilen delta ve funnel tipi feromon tuzaklara H. armigera'nın ilk erginleri 08.07.2019 tarihinde Mütevelli’deki parselde yakalanmış ve ilk sayım tarihinden (13.07.2019) itibaren örnekleme yerlerinin tümündeki tuzaklarda erginler kaydedilmiş ve hasat tarihine (19.10.2019) kadar erginler tuzaklara yakalanmaya devam etmiştir (Tablo 2 ve Şekil 2). 
JOTAF/ Journal of Tekirdag Agricultural Faculty, 2020, 17(3)

Tablo 2. Deneme parsellerinde 2019 yulında delta ve funnel tuzaklara yakalanan Helicoverpa armigera ergin sayıları (Adet/Tuzak/Hafta)

Table 2. Helicoverpa armigera adult numbers caught in delta and funnel traps in trial plots in 2019 (Number / Trap /Week)

\begin{tabular}{lcccccccccc}
\hline Parseller & \multicolumn{2}{c}{ Karaağaçl } & \multicolumn{2}{c}{ Selimşahlar } & \multicolumn{2}{c}{ Yenimahmudiye } & Mütevelli & \multicolumn{2}{c}{ Veziroğlu } \\
\hline Tuzaklar & Delta & Funnel & Delta & Funnel & Delta & Funnel & Delta & Funnel & Delta & Funnel \\
\hline 13.07 .2019 & 1 & 2 & 1 & 3 & 1 & 1 & 1 & 1 & 1 & 3 \\
\hline 20.07 .2019 & 1 & 3 & 0 & 3 & 1 & 1 & 2 & 1 & 1 & 3 \\
\hline 27.07 .2019 & 4 & 1 & 1 & 4 & 1 & 2 & 4 & 1 & 1 & 5 \\
\hline 03.08 .2019 & 2 & 3 & 1 & 3 & 0 & 2 & 1 & 2 & 1 & 5 \\
\hline 10.08 .2019 & 3 & 5 & 2 & 3 & 2 & 3 & 2 & 4 & 3 & 7 \\
\hline 17.08 .2019 & 2 & 8 & 4 & 7 & 2 & 3 & 3 & 5 & 4 & 8 \\
\hline 24.08 .2019 & 4 & 10 & 3 & 7 & 2 & 4 & 3 & 9 & 3 & 12 \\
\hline 31.08 .2019 & 2 & 6 & 1 & 4 & 1 & 3 & 2 & 5 & 1 & 7 \\
\hline 06.09 .2019 & 3 & 4 & 3 & 3 & 2 & 3 & 3 & 3 & 2 & 6 \\
\hline 13.09 .2019 & 1 & 3 & 1 & 2 & 1 & 1 & 1 & 2 & 1 & 3 \\
\hline 20.09 .2019 & 5 & 13 & 4 & 9 & 3 & 6 & 4 & 8 & 6 & 15 \\
\hline 27.09 .2019 & 2 & 5 & 2 & 3 & 1 & 3 & 1 & 4 & 3 & 7 \\
\hline 05.10 .2019 & 1 & 2 & 1 & 3 & 1 & 1 & 1 & 1 & 1 & 3 \\
\hline 12.10 .2019 & 1 & 2 & 1 & 3 & 1 & 1 & 1 & 1 & 1 & 3 \\
\hline 19.10 .2019 & 0 & 2 & 0 & 1 & 1 & 1 & 0 & 1 & 1 & 1 \\
\hline Toplam & 32 & 69 & 25 & 58 & 20 & 35 & 29 & 48 & 30 & 88 \\
\hline Genel toplam & $\mathbf{1 0 1}$ & & $\mathbf{8 3}$ & & $\mathbf{5 5}$ & & $\mathbf{7 7}$ & $\mathbf{1 1 8}$ \\
\hline
\end{tabular}

Örnekleme yapılan pamuk alanlarında Ağustos ayı ortasında ve Eylül ayının sonunda olmak üzere tüm parsellerde her iki feromon tuzağına yakalanan erginler iki tepe noktası oluşturmuştur. Temmuz ayında ise tuzaklara az sayıda ergin yakalandığı için belirgin olmamakla birlikte bir dalgalanma gözlenmiştir. H. armigera ergin popülasyon yoğunluğu, ağırlıklı olarak pamuğun olgunlaşma döneminde varlığını hissettirmiştir. Çukurova bölgesinde pamukta yapılan bir çalışmada Yeşilkurt'un pamuğun koza oluşturma ve olgunlaştırma döneminde ortaya çıktığı, Temmuz- Ağustos döneminde iki döl verdiği tespit edilmiştir (Atakan ve Boyacı, 2017). Manisa ilinde yıllara göre farklı olmak birlikte pamuk alanlarında H. armigera erginlerinin Temmuz, Ağustos ve Ekim ayı başında olmak üzere 3 uçuş gerçekleştirdiği bildirilmiştir (Koçlu ve Karsavuran,2000). Diyarbakır ili pamuk alanlarında ise $H$. armigera ergin sayısının mevsim başında yükssek yoğunluğa ulaştığı tespit edilmiştir (Akyıldız ve Bayhan, 2018). Çalışma alanı ile aynı enlemde yer alan Yunanistan'dan H. armigera erginlerinin Mayıs-Ekim aylarında tuzaklarda yakalandığı belirlenmiştir (Tsitsipis ve Alexandri, 1990). Ülkemizde yapılan diğer çalışmalarda ise ergin uçuş periyodunun bölgelere göre farklı olduğu görülmüştür (Öngören ve ark., 1977); (Mart ve ark., 2000). 
Manisa ili pamuk alanlarında Helicoverpa armigera Hübner (Lepidoptera; Noctuidae)'nın bazı biyolojik özelliklerinin belirlenmesi

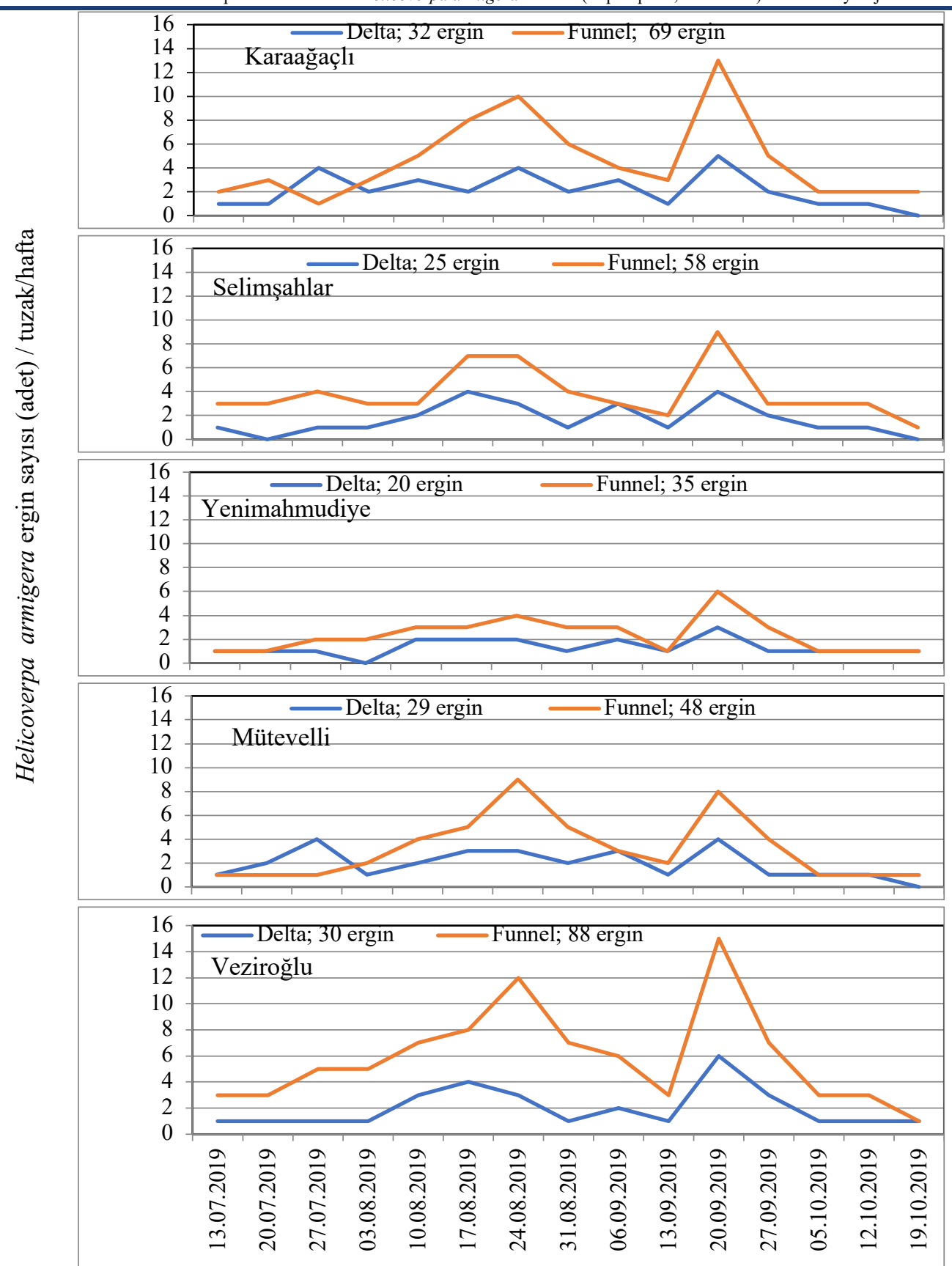

Figure 2- Adult population development of Helicoverpa armigera caught in delta and funnel traps in different cotton plots in Manisa province

Şekil 2- Manisa ilinde farklı pamuk parsellerinde delta ve funnel tuzaklara yakalanan Helicoverpa armigera ergin popülasyon gelişmesi

Beş pamuk parselinde delta tuzaklara toplam 136 adet ergin yakalanırken funnel tuzaklarda bu sayı 298 adet olarak kaydedilmiştir. Funnel tuzaklara yakalanan toplam ergin sayısı delta tuzaklara göre yüksek çıkmıştır. Pamuk alanlarında yakalanan toplam 434 adet erginin \%31,33 delta ve \%68,66's1 ise funnel tipi tuzaklarda kaydedilmiştir. Örnekleme yapılan pamuk parselleri karşılaştırıldığında, mevsim boyunca tuzaklara yakalanan 434 adet $H$. armigera erginin \%27,2'si Veziroğlu pamuk parselindeki tuzaklarda yakalanmıştır. Bunu \%23,3 adet ergin ile Karaağaçlı'daki parsel izlemiştir.

Manisa ili Şehzadeler ilçesi sınırlarında yer alan 5 farklı pamuk tarlasında 2019 yılı vejetasyon döneminde delta ve funnel tipi feromon tuzakları yakalanan H. armigera ergin sayıları istatistiksel olarak karşılaştırılmıştır (Şekil 3). Beş pamuk parselinde delta tuzaklara $(n=75)$ yakalanan ortalama ergin sayısı $(1,8 \pm 0,15)$ ile funnel 
tuzaklara $(\mathrm{n}=75)$ yakalanan ortalama ergin sayıs $(3,9 \pm 0,34)$ arasındaki fark istatistiksel olarak $\mathrm{F}=33,7 \mathrm{P}=0,00)$ önemli bulunmuştur. Buna karşın tüm parsellerde delta tuzaklara yakalanan $H$. armigera ortalama ergin sayısı $(\mathrm{n}=15)$ arasındaki fark $(\mathrm{F}=2,64 \mathrm{P}=0,07)$ istatistiksel olarak önemsiz çıkmıştır.

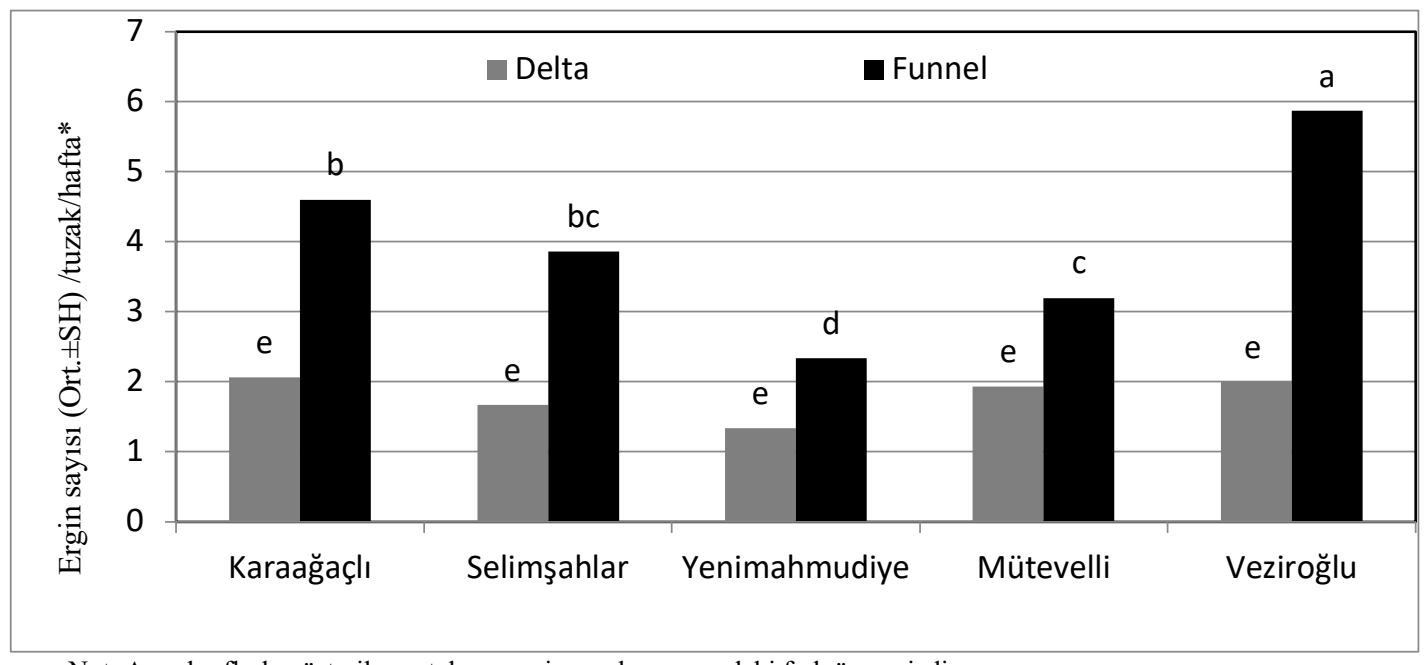

Not: Aynı harflerle gösterilen ortalama ergin sayıları arasındaki fark önemsizdir.

Figure 3. Comparison of Helicoverpa armigera adult (Mean $\pm S E)$ numbers captured with delta and funnel traps in five cotton plots in Manisa province $(P<0,05)$.

Şekil 3. Manisa ilinde beş pamuk parselinde delta ve funnel tuzaklarla yakalanan Helicoverpa armigera ergin (Ort. \pm SH) sayılarının karşılaştırılması $(P<0,05)$.

Funnel tuzaklara haftalı $(\mathrm{n}=15)$ yakalanan $H$. armigera ergin sayısı arasındaki fark $(\mathrm{F}=18,993 ; \mathrm{P}=0,00)$ ise istatistiksel olarak anlamlı bulunmuştur $(\mathrm{P}<0,05)$. En yüksek ergin sayısı Veziroğlu $(5,867 \pm 0,965$ adet $)$ pamuk

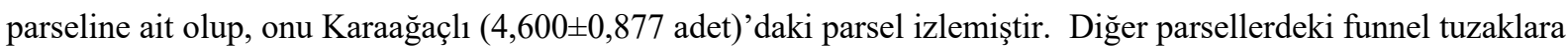
yakalanan ergin sayıları da birbirinden farklı çıkmıştır. En az ergin Yenimahmudiye'deki (2,333 $\pm 0,374$ adet) pamuk parselinde kaydedilmiştir. Parsel başına her iki tuzağa yakalanan toplam ergin sayısı da funnel tuzakların etkisiyle genel olarak birbirinden farklı çıkmıştır. H. armigera erginlerini yakalamada funnel tuzaklar tüm parsellerde en iyi sonucu vermiştir. H. armigera erginlerini yakalamada funnel, delta ve kanat tipi tuzakların karşılaştırıldığı Hatay ili pamuk alanlarında en iyi sonucun funnel tuzaklarla alındığı bildirilmiştir (Mart ve ark., 2000).

Tablo 1'de gerek H. armigera'ya karşı ve gerekse diğer emici zararlılara karşı beş örnekleme parselinde de aynı tarihlerde ve aynı sayıda insektisitler kullanılarak ilaçlama yapılmıştır. BA 440 pamuk çeşidinin ekili olduğu Veziroğlu ve Karaağaçlı'daki pamuk parsellerinde $H$. armigera'nın ergin ve ergin öncesi dönemlerine ait birey sayısı diğer parsellere göre yüksek çıkmıştır. Ancak, Carisma pamuk tohumunun kullanıldığı parsellerde de yakalanan ergin sayısı da birbirinden farklı bulunmuştur. Dolayısıyla ergin sayısındaki farkın çeşit özelliğinden kaynaklanıp kaynaklanmadığı yönünde bir kanaate varılamamıştır.

Örnekleme parsellerinde 2019 yılı pamuk yetiştirme periyodu boyunca $H$. armigera'nın ergin, yumurta ve larvaları ile genel predatör türlere ait sayısal değerler Tablo 3'te verilmiştir. Tüm parsellerde 434 adet ergin tuzaklara yakalanmış olup, buna karşılık 58 adet yumurta ve 15 adet larva sayılmıştır. Söz konusu larva ve yumurtaların büyük bölümü ergin popülasyon yoğunluğunun yüksek olduğu dönemlerde kaydedilmiştir. Zira en fazla erginin yakalandığı Verziroğlu (18 yumurta ve 7 larva) ve Karaağaçlı (14 yumurta ve 3 larva) parsellerinde daha fazla yumurta ve larva sayılmıştır. Bu durum, örnekleme parsellerindeki $H$. armigera ergin sayıları ile yumurta ve larva sayılarının oransal olarak paralel olduğunu göstermiştir.

Yumurta ve larva sayımlarının yapıldığı 3 metre bitki sırasında pamukta zararlı olan A. gossypii, T. urticea ve B. tabaci gibi emici zararlı türlerin predatörü olan C. carnea yumurtaları tüm parsellerde birbirine yakın sayıda 

kaydedilmiş ve toplam 598 adet sayılmıştır. Benzer şekilde Çanakkale ili pamuk alanlarında yapılan bir çalışmada C. carnea popülasyon yoğunluğunun diğer genel predatörlerden yüksek olduğu bildirilmiştir (Özpınar ve ark., 2017a). C. carnea'nın pamuktaki zararlılara karşı kullanılan insektisitlere diğer predatör türlerden daha toleranslı olduğu yapılan çalışmalarda tespit edilmiştir (Sayyed ve ark., 2010). Tüm bu çalışmalardan da anlaşıldığı üzere $C$. carnea'nın pamuk alanlarında zararlıların kontrolünde ümit var bir durum yaratmıştır.

\section{Tablo 3. Manisa ili pamuk alanlarında 2019 yılı vegetasyon döneminde Helicoverpa armigera'nın yumurta, larva ve predatör türlere ait sayısal değerler.}

Table 3. Numerical values of egg, larvae and predator species of Helicoverpa armigera in cotton fields in Manisa province in 2019

\begin{tabular}{lrccc}
\hline \multirow{2}{*}{$\begin{array}{l}\text { Örnekleme } \\
\text { yerleri }\end{array}$} & \multicolumn{3}{c}{ Helicoverpa armigera Hübner } & Chrysoperla carnea \\
\cline { 2 - 5 } & Ergin & Yumurta* & Larva* $^{*}$ & yumurtas1* \\
\hline Karaağaçlı & 101 & 14 & 3 & 123 \\
\hline Selimşahlar & 83 & 10 & 1 & 121 \\
\hline Yenimahmudiye & 55 & 10 & 1 & 123 \\
\hline Mütevelli & 77 & 12 & 3 & 120 \\
\hline Veziroğlu & 118 & 12 & 7 & 111 \\
\hline Toplam & $\mathbf{4 3 4}$ & $\mathbf{5 8}$ & $\mathbf{1 5}$ & $\mathbf{5 9 8}$ \\
\hline
\end{tabular}

* pamukta 3 metre bitki sırasındaki ortalama değerler.

Parseller esas alınarak örnekleme süresince haftalık sayımlarla elde edilen $H$. armigera'nın yumurta ve larva popülasyon gelişmesiyle C. carnea yumurta yoğunluğu arasındaki ilişki Şekil 4'te verilmiştir. Farklı parsellerde H. armigera'nın yumurta ve larva yoğunluğu ile C. carnea yumurta sayısının gelişimi arasında bir paralellik olduğu görülmüştür. C. carnea'nın birçok zararlı tür ile birlikte pamuk alanlarında H. armigera'nın yumurta ve erken dönem larvaları üzerinde önemli bir predatör olduğu bildirilmiştir (Bar ve ark., 1979); (Pappas ve ark., 2007); (Hassanpour ve ark., 2011). Çalışma alanında da A. gossypii ve diğer emci türlerin varlığı nedeniyle mevsim başında 5 kez insektisit kullanılmış ancak C. carnea'nın yumurta sayısı belli düzeyde devam etmiştir. Ağustos ortası ile Eylül ayı sonunda ise $H$. armigera larva yoğunluğundaki artış nedeniyle üreticiler tarafından 2 kez daha ilaçlama yapılmıştır. İlaçlamalarla birlikte C. carnea yumurta sayısındaki kısmi azalmaya rağmen, yumurta yoğunluğu belli bir düzeyde devam etmiştir. Zira bu konuda yapılan çalışmalardan da benzer bulguların olduğu, Çukurova koşullarında pamuk tarlalarında erken dönemlerde A. gossypii üzerinde C. carnea'nın yaygın olarak bulunduğu (Atakan, 2000) ve uygulanan insektisitlerden C. carnea yumurtalarının larva ve erginlere göre daha az etkilendiği bildirilmiştir (Kaitazov ve Kharizanov, 1976).

4.Sonuç

Bu çalışmada, 2018 yılında incelenen 5 örnekleme parselinde toplam 16 ergin tuzaklara yakalanmıştır. $H$. armigera popülasyon yoğunluğunun düşük düzeyde kalmış ve zararlıya karşı herhangi bir mücadele programı uygulanmamıştır. B durum H. armigera'nın salgın yılında olmamasına bağlanmıştır. Çalışmanın ikinci yılında ise temmuz ayının ilk haftasından itibaren hasadın yapıldığı ekim ortalarına kadar örnekleme parsellerinin hepsinde tuzaklara H. armigera erginleri yakalanmış, Ağustos ayı ortasında ve Eylül ayı sonunda olmak üzere 2 tepe noktası meydana gelmiştir. Dolayısıyla ülkemizde sıklıkla yaşandığı üzere $H$. armigera popülasyon yoğunluğunu tahmin etmede bir önceki yılın referans alınamayacağı görülmüştür.

Örnekleme parsellerinin tümünde erginleri yakalamada funnel tipi tuzaklar delta tipi tuzaklara göre oldukça başarılı bulunmuştur. Başlangıçta, düşük maliyetleri nedeniyle delta tuzaklar avantajlı gibi görünse de funnel tuzakların arazide korunmaları halinde daha uzun süre kullanılma olanağı nedeniyle tercih edilecektir. Diğer yandan, aynı feromon kapsülü içeren farklı tuzak tipinde oldukça birbirinden farklı sayıda H. armigera erginlerini yakalamış olması, örnekleme araçlarının önemini ortaya koymuştur. 
JOTAF/ Journal of Tekirdag Agricultural Faculty, 2020, 17(3)

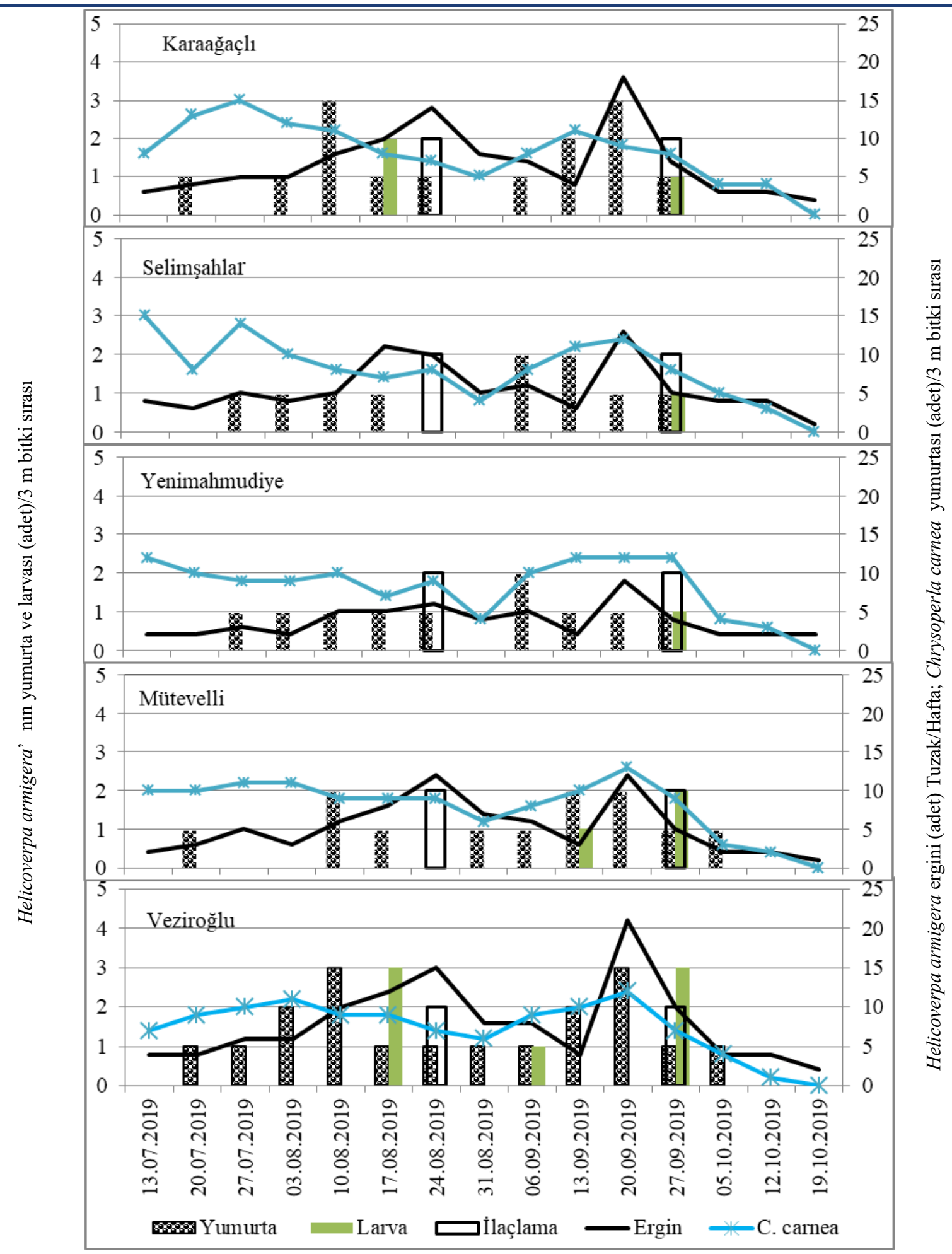

Şekil 4. Manisa ilinde farkl pamuk parsellerinde Helicoverpa armigera'nin ergin, yumurta ve larvalart ile Chrysoperla carnea'nin yumurta saytsi (adet/haftalık)

Figure 4. The number of adults, eggs and larvae of Helicoverpa armigera and eggs of Chrysoperla carnea in different cotton fields in Manisa province (number / week)

Diğer taraftan, BA 440 pamuk çeşidinin ekili olduğu Karaağaçlı ve Veziroğlu parsellerinde $H$. armigera popülasyon yoğunluğu Carisma çeşidi ekili olan diğer parsellere göre yüksek olması dikkati çekmiştir. BA 440 

pamuk çeşidinin yapraklarının daha tüylü olması H. armigera'nın yumurta bırakması için bir tercih nedeni olabileceği şeklinde değerlendirilmiş̧ir.

Tuzaklara yakalanan $H$. armigera ergin sayısıyla 3 metre bitki sırasındaki $H$. armigera yumurta ve larva sayısı arasında beklenen paralellik oluşmamıştır. Özellikle funnel tuzaklarda yakalanan ergin sayısıyla $H$. armigera'nın aynı parsellerdeki yumurta ve larva sayısı arasında önemli bir fark oluşmuştur. Buna rağmen, H. armigera ergin sayısının yüksek olduğu ağustos ayının 2. yarısında ve eylül sonlarında olmak üzere 2 kez ilaçlama yapılmıştır. Mevsim başında emici zararlı böceklere karşı tüm parsellerde 5 farklı tarihte aynı insektisitler uygulanmıştır. Diğer parsellere göre $H$. armigera popülasyon yoğunluğunun yüksek olduğu Karaağaçlı ve Veziroğlu parsellerinde ilk örnekleme tarihlerinde C. carnea yumurta sayısı kısmen düşük de olsa, genel olarak, parsellerin tümünde yüksek sayıda yumurta kaydedilmiştir. C. carnea yumurta sayısı ile $H$. armigera'nın yumurta ve larva sayısındaki değişim arasında bir paralellik olduğu görülmüştür. Zira, Bakthavatsalam ve ark., (2000) C. carnea'nın $H$. armigera'nın önemli bir predatörü olduğunu bildirmiştir.

Salgın yıllarında pamuk bitkisinde önemli ürün kayıplarına neden olan H. armigera ile kimyasal mücadelenin kaçınılmaz olduğu ve yapplan ilaçlamaya rağmen, $C$. carnea yumurta yoğunluğunun yüksek düzeyde seyretmiş olması mücadelenin başarısı için ümit var bir durum yaratmıştır.

\section{Teşekkür}

Bu makale Çanakkale Onsekiz Mart Üniversitesi, Bilimsel Araştırmalar Koordinasyon Birimi tarafından desteklenen FYL-2018-2591 nolu projeden üretilmiştir. 


\section{Kaynakça}

Anonim, (2017). Manisa İl Tarım ve Orman Müdürlüğ̈̈ (https://manisa.tarimorman.gov.tr/) Tarımsal Veriler. Erişim tarihi:05.02.2020.

Akyıldız, M., Bayhan, E. (2018). Diyarbakır ili pamuk ekim alanlarında bulunan Yeşilkurt, Helicoverpa armigera (Hübner) (Lepidoptera: Noctuidae)'un popülasyon dalgalanmasının belirlenmesi. Harran Tartm ve Gıda Bilimleri Dergisi, 22 (2): 186-195.

Atakan, E. (2000). Within plant distribution of predators Chrysoperla carnea, Deraeocoris pallens and Orius niger on cotton. Türkiye Entomoloji Dergisi 24 (4):267-277.

Atakan, E., Boyacı, K. (2017). Pamukta farklı ekim şekli ve ekim zamanının Yeşilkurt (Helicoverpa armigera Hubn. Lepidoptera: Noctuidae) popülasyonuna ve bitki gelişmesine etkisinin araştrrılması. Türkiye Entomoloji Bülteni, 7 (2): 143-156.

Bakthavatsalam, N., Singh, S. P., Tandon, P. L., Chaudhary, M., Preethi, S. (2000). Synomone mediated behavioural responses of Chrysoperla carnea (Stephens) (Neuroptera: Chrysopidae) to cotton infested by ((Helicoverpa armigera (Hübner) (Lepidoptera: Noctuidae)). Journal of Biological Control 14 (2): 1-6.

Bar, D., Gerling, D., Rossler, Y. (1979). Bionomics of the principal natural enemies attacking of Heliothis armigera in cotton fields in Isreal. Environmental Entomology 8 (3):468-474.

Ferreira A.J., Carvalho, G. A, Botton, M., Lasmar, O. (2006). Selectivity of insecticides used in apple orchards to two populations of Chrysoperla externa (Hagen, 1861) (Neuroptera: Chrysopidae). Ciência Rural 36 (2): 378-384.

Göven, M. A., Efil, L. (1994). Dicle vadisi pamuk alanlarında zararlı Yeşilkurt (Heliothis armigera Hübn.) (Lepidoptera: Noctuidae)'un doğal düşmanları ve etkinlikleri üzerinde araştırmalar. Türkiye 3. Biyolojik Mücadele Kongresi, 25-28 Ocak, P. 449-457, İzmir, Türkiye.

Hassanpour, M., Mohaghegh, J., Iranipour, S., Ganbalani, G. N., Enkegaard, A. (2011). Functional response of Chrysoperla carnea (Neuroptera: Chrysopidae) to Helicoverpa armigera (Lepidoptera: Noctuidae): Effect of prey and predator stages. Insect Science 18 (2):217-224

IBM Crop, (2015). IBM SPSS Statistics 23.0 for Windows, 22.0 ed. IBM Corp., Armonk, NY.

Karaat, Ş., Göven, M. A., Mart, C. (1986). Güneydoğu Anadolu Bölgesi’nde pamuk ekim alanlarında yararlı türlerin genel durumları. Türkiye 1. Biyolojik Mücadele Kongresi, 12-14 Şubat, P, 186-194, Adana, Türkiye.

Kaitazov A., Kharizonav, A. (1976). The possibilities for using Chrysopidae. Rastelin Zashchita, 24 (11):22-25.

Karim, S. (2000). Management of Helicoverpa armigera: A Review and prospectus for Pakistan. Pakistan Journal of Biological Sciences 3 (8): 1213-1222.

Koçlu, T., Karsavuran, Y. (2000). Heliothis armigera Hbn.,. (Lepidoptera: Noctuidae)'nın Manisa ilinde biyolojisi ve popülasyon düzeyi. Türkiye Entomoloji Dergisi 24 (3):179-194.

Liu, Z., Li, D., Gong, P., Wu, K. (2004). Life table studies of the cotton bollworm, Helicoverpa armigera (Hübner) (Lepidoptera: Noctuidae), on different host plants. Environmental Entomology 33 (6): 1570-1576.

Mart, C., Arslan, M. M., Eroğlu, N., Doğanlar, O. (2000). Pamuk alanlarında Yeşilkurt, Heliothis armigera Hbn. (Lepidoptera: Noctuidae)'un popülasyon takibinde eşeysel çekici tuzakların kullanım imkanları üzerinde araştırmalar. Kahramanmaraş Sütçü İmam Üniversitesi, Fen ve Mühendislik Dergisi 3 (2): 145-153.

Öngören, K., Kaya, N., Türkmen, Ş. (1977). Ege Bölgesi’nde domateslerde zarar yapan Yeşilkurt (Heliothis armigera Hübner)'un morfolojisi, biyolojisi ve mücadelesi üzerinde araştırmalar. Bitki Koruma Bülteni 17 (1): 3-28.

Özgür, F., Şekeroğlu, E., Gençer, O., Göçmen, H., Yelin, D., İşler, N. (1988). Önemli pamuk zararlılarının pamuk çeşitlerine ve bitki fenolojisine bağlı olarak popülasyon gelişmelerinin araştırılması. TÜBİTAK, Doğa Dergisi 12 (1): 48-74.

Özpınar A., Şahin, A. K., Polat, B., Özpınar, S. (2017a). Troia (Çanakkale) Milli Park alanında polifag zararlı türlerle entegre mücadele olanaklarının araştırılması. ÇOMÜ, Ziraat Fakültesi Dergisi 5 (1) :49-57.

Özpınar A., Polat, B., Şahin, A. K., Özpınar, S. (2017b). Çanakkale ili domates alanlarında canavarotu (Orobanche ramosa L.) ve Phytomyza orobanchia Kaltenbach (Diptera; Agromyzidae) arasındaki ilişkinin belirlenmesi. Namık Kemal Üniversitesi, Tekirdăg Ziraat Fakültesi Dergisi 14 (1) :48-53.

Pappas, M. L., Broufas, G.D., Koveos, D.S. (2007). Effects of various prey species on development, survival and reproduction of the predatory lacewing Dichochrysa prasina (Neuroptera: Chrysopidae). Biological Control 43 (2):163-170.

Sayyed, A. H., Pathan, A. K., Faheem, U. (2010). Cross-resistance, genetics and stability of resistance to deltamethrin in a population of Chrysoperla carnea from Multan, Pakistan. Pesticide Biochemistry and Physiology 98 (3) : 325-332.

Sechser, B., Ayoub, S., Monuir, N. (2003). Selectivity of emamectin benzoate to predators of sucking pests on cotton. Zeitschrift für Pflanzenkrankheiten und Pflanzenschutz 110 (2): 184-194.

Theiling K. M., Croft, B. A. (1988). Pesticide side-effects on arthropod natural enemies: A database summary. Agriculture, Ecosystem and Environment 21 (3-4): 191-218.

Tilman, P. G., Mulroney, J. E. (2000). Effect of Selected insecticides on the natural enemies Coleomegilla maculata and Hippodamia convergens (Coleoptera: Coccinellidae), Geocoris punctipes (Hemiptera: Lygaeidae), and Bracon mellitor, Cardiochiles nigriceps, and Cotesia marginiventris (Hymenoptera: Braconidae) in cotton. Journal of Economic Entomology 93 (6): 1638-1643. 
Memiş \& Özpınar

Manisa ili pamuk alanlarında Helicoverpa armigera Hübner (Lepidoptera; Noctuidae)'nın bazı biyolojik özelliklerinin belirlenmesi Tsitsipis, J. A., Alexandri, M. (1990). Monitoring Helicoverpa armigera, Scotia ipsilon and Scotia segetum by pheromone traps in Greece, Comparison of Two Kinds of Traps. OILB SROP WPRS Bulletin 13 (3): 54-61.

TUIK, (2020). Türkiye İsatatistik Kurumu, (https://biruni.tuik.gov.tr/medas/?kn=92\&locale=tr) Erişim tarihi:07.02.2020.

Zalucki, M. P., Murray, D.A.H., Gregg, P. C., Fitt, G. P., Twine, P. H., Jones. C. (1994). Ecology of Helicoverpa armigera (Hubner) and H. punctigera (Wallengren) in the Inland of Australia: larval sampling and host plant relationships during winter and spring. Australian Journal of Zoology 42 (3): 329-346. 